\title{
Impact of Stratospheric Sudden Warming on East Asian Winter Monsoons
}

\author{
Quanliang Chen, Luyang Xu, and Hongke Cai \\ College of Atmospheric Science, Chengdu University of Information Technology and Plateau Atmospheric and \\ Environment Laboratory of Sichuan Province, Chengdu 610225, China
}

Correspondence should be addressed to Quanliang Chen; chenql@cuit.edu.cn

Received 15 January 2015; Revised 22 March 2015; Accepted 29 March 2015

Academic Editor: Jieshun Zhu

Copyright (C) 2015 Quanliang Chen et al. This is an open access article distributed under the Creative Commons Attribution License, which permits unrestricted use, distribution, and reproduction in any medium, provided the original work is properly cited.

\begin{abstract}
Fifty-two Stratospheric sudden warming (SSW) events that occurred from 1957 to 2002 were analyzed based on the 40-year European Centre for Medium-Range Weather Forecasts Reanalysis dataset. Those that could descent to the troposphere were composited to investigate their impacts on the East Asian winter monsoon (EAWM). It reveals that when the SSW occurs, the Arctic Oscillation (AO) and the North Pacific Oscillation (NPO) are both in the negative phase and that the tropospheric circulation is quite wave-like. The Siberian high and the Aleutian low are both strengthened, leading to an increased gradient between the Asian continent and the North Pacific. Hence, a strong EAWM is observed with widespread cooling over inland and coastal East Asia. After the peak of the SSW, in contrast, the tropospheric circulation is quite zonally symmetric with negative phases of AO and NPO. The mid-tropospheric East Asian trough deepens and shifts eastward. This configuration facilitates warming over the East Asian inland and cooling over the coastal East Asia centered over Japan. The activities of planetary waves during the lifecycle of the SSW were analyzed. The anomalous propagation and the attendant altered amplitude of the planetary waves can well explain the observed circulation and the EAWM.
\end{abstract}

\section{Introduction}

Stratospheric sudden warming (SSW) is an intriguing phenomenon of winter stratospheric circulation. Since it was first discovered in 1952 by Scherhag [1], it has been recognized as one of the critical phenomena that could influence hemispheric circulation patterns. Polar stratospheric temperature rises sharply when SSW occurs, and stratospheric circulation patterns linked to temperature changes shift dramatically. SSW events can be divided into major and minor warming events, based on the degree of warming. Charlton and Polvani [2] classified major warming events into those that either do or do not split the stratospheric polar vortex based on the zonal wind at $60^{\circ} \mathrm{N}$ and $10 \mathrm{hPa}$. Matthewman et al. [3] found that vortex-splitting events are typically barotropic, with the vortex split occurring nearly simultaneously over a large altitude range $(20-40 \mathrm{~km})$, while displacement events are characterized by a very clear baroclinic structure.

Abnormal circulation caused by some specific SSW events is able to propagate downward to influence the tropospheric weather and climate. Early in the 1970s, Quiroz [4] found that anomalous stratospheric zonal anticyclonic circulation in high latitudes occurs along with SSW, and this anomaly extends from the stratosphere to the ground and affects tropospheric weather systems. Baldwin and Dunkerton [5] considered that Arctic Oscillation (AO), which is the critical mode that couples the stratosphere and troposphere, has a significant relationship with SSW. They suggested that SSW causes the AO index to become negative and return to positive slowly. They also pointed out the potential role of the stratosphere in the tropospheric weather forecasts during both the weak and strong vortex events. Later, Baldwin et al. $[6,7]$ further found that SSW could lead to higher temperature and geopotential height in the polar region and weaken the stratospheric AO.

Major SSW events can cause significant changes in the stratospheric polar region and lead to the anomaly of Northern Hemispheric AO transmission to the troposphere, thereby affecting weather and climate in the troposphere. $\mathrm{Li}$ et al. [8] found that, after a major SSW event, temperature 
and height anomalies in the polar stratosphere can lead to downward $\mathrm{AO}$, which may result in stronger Siberian high and Aleutian low, and a deeper westward shifted midtropospheric East Asian trough. Deng et al. [9] analyzed the linkage between the SSW and AO and found that the uppertropospheric East Asian jet stream is strengthened and the East Asian trough is deepened during SSW. Mitchell et al. [10] developed a new classification technique of weak vortex events based on the distribution of potential vorticity and further divided such events into vortex displacements and vortex splits. They suggested that vortex splitting events are correlated with surface weather and can lead to positive temperature anomalies that exceed $1.5 \mathrm{~K}$ over eastern North America and negative anomalies that exceed $-3 \mathrm{~K}$ over Eurasia and that the corresponding signals are weaker during displacement events. Wang and Chen [11] studied the cold winter in 2009 and suggested that this event is accounted for by the extreme negative AO at surface level and that some relatively weaker stratospheric anomalies can also propagate downward and influence the troposphere. From the perspective of mass circulation, some recent studies provided a clear physical picture on the linkage between the stratospheric circulation anomalies and the Northern Hemispheric cold air outbreaks $[12,13]$.

China is located in East Asia, and the East Asian winter monsoon (EAWM) is the world's strongest winter monsoon system $[14,15]$. The EAWM is generally considered to be the driver of the East Asian atmospheric circulation and is related to cold air moving eastward and southward from the Siberian high [14]. Previous scholars have shown that many factors including external forces and internal dynamic processes can affect the EAWM $[14,15]$. Some recent studies [16-20] suggested that the changes of EAWM are closely linked to the winter $\mathrm{AO}$. The EAWM is strong during the negative phase of AO and vice versa. The North Pacific Oscillation (NPO) and its tropospheric embodiment, the western Pacific (WP) pattern, are other important factors that influence the EAWM [21-23]. They are featured with an equivalent barotropic structure in summer but tilt slightly westward with height during the other three seasons [21]. The positive phase of NPO favors significant southerly anomalies along the coasts of East Asia during the boreal winter and may bring warm moist air from the south [21].

It is well known that the troposphere and the stratosphere are dynamically coupled because of the vertical transmission of atmospheric planetary waves in the boreal winter. After Thompson and Wallace discovered AO [24, 25], observation and simulation results both indicate that the anomalies that occur in the stratosphere are able to propagate downward to the troposphere, affecting climate and weather when accompanied by the AO signal [26-28]. However, not all the stratospheric AO events and SSW events are linked with the subsequent tropospheric cold events or low temperature events [26-28]. Besides, most of these studies focused on North America or Europe, and fewer studies were carried on for East Asia. In fact, the EAWM has a very close relationship with the AO and the stratosphere [16-20, 29], implying that the stratosphere is very likely to influence the EAWM. Moreover, it is interesting to explore this issue because the long-lasting stratospheric anomalies may provide valuable information for the medium-range weather prediction of the EAWM. Therefore, this study aims to explore the possible relationship between the SSW (stratospheric AO) and the EAWM, focusing on the period of both during and after the peak of the SSW. Specifically, we divided the 52 SSW events during 1957-2002 into those that could and could not propagate downward to the troposphere and analyzed the changes of the East Asian winter monsoon during and after the peak of the downward propagating SSW events. In order to understand the mechanism that links the EAWM and the SSW, the activity of planetary waves and the associated Eliassen-Palm (EP) flux were also investigated.

\section{Data and Methods}

Data used in this study are from the 40-year European Centre for Medium-Range Weather Forecast Reanalysis (ERA-40) dataset that contains 45 years (1957-2002). It has a horizontal resolution of $2.5^{\circ} \times 2.5^{\circ}$ and extends from 1000 to $1 \mathrm{hPa}$ with 23 pressure levels. The data used in this study include the geopotential field, the temperature field, and the zonal and meridional wind fields.

According to the World Meteorological Organization's stipulation in 1963, in order for a warming event to be qualified as SSW, it needs to meet two criteria: (1) a zonal mean temperature of $60^{\circ} \mathrm{N}$ to polar reverses its meridional gradient at $10 \mathrm{hPa}$ or lower and (2) the polar vortex weakens and moves south, while, since the polar region is controlled by a warm high, the circulation turns easterly instead of westerly. These criteria can be expressed as follows:

$$
\begin{aligned}
\Delta[T] & =[T]_{90^{\circ} \mathrm{N}}-[T]_{60^{\circ} \mathrm{N}} \\
\Delta[H] & =[H]_{90^{\circ} \mathrm{N}}-[H]_{60^{\circ} \mathrm{N}},
\end{aligned}
$$

where [] indicates the zonal mean. When $\Delta[T]>0$, $\Delta[H]>0$-that is, both zonal mean temperature and the corresponding zonal mean geopotential meridional gradient reverse in $60^{\circ} \mathrm{N}$ to polar regions; we define it as a major SSW event. If only $\Delta[T]>0$, but $\Delta[H]<0$, then the event is defined as a minor SSW event. Thirty-one strong and 21 minor SSW events were identified and analyzed for the 45 winters during 1957-2002, according to the definition above (see Table 1).

In addition, we define an SSW event as a downward propagating event if it meets both of the following criteria [30].

(1) The maximum anomalies of geopotential height in the polar region $\left(70^{\circ} \sim 90^{\circ} \mathrm{N}\right)$ at $10 \mathrm{hPa}$ lag behind the maximum anomalies of $1 \mathrm{hPa}$ by at least one day.

(2) The maximum anomalies of geopotential height in the polar region $\left(70^{\circ} \sim 90^{\circ} \mathrm{N}\right)$ at $10 \mathrm{hPa}$ lead the maximum anomalies of $100 \mathrm{hPa}$ by at least one day.

Twenty-eight downward propagating events were selected from the 52 SSW events according to the criteria above, and they are listed in Table 1 . As we can see, 21 out of 31 major SSW events could propagate downward, but only 
TABLE 1: All SSW events and the downward propagating SSW events.

\begin{tabular}{|c|c|c|c|c|}
\hline Year & Onset of major SSW & Termination of major SSW & Onset of minor SSW & Termination of minor SSW \\
\hline 1958 & $2-6,11-22^{\mathbf{\Lambda}}$ & $2-14,12-12^{\mathbf{4}}$ & - & - \\
\hline 1960 & $1-4^{\mathbf{A}}, 12-9$ & $1-24^{\mathbf{4}}, 12-26$ & - & - \\
\hline 1962 & - & - & $2-4,12-8$ & $2-23,12-17$ \\
\hline 1963 & $1-25^{\wedge}$ & $2-11^{\mathbf{4}}$ & - & - \\
\hline 1965 & $12-4$ & $12-23$ & - & - \\
\hline 1967 & $12-30^{\mathbf{4}}$ & $1968-1-25^{\mathbf{A}}$ & - & - \\
\hline 1968 & $11-18$ & $12-3$ & - & - \\
\hline 1970 & $1-1^{\mathbf{\Delta}}$ & $2-1^{\mathbf{\Delta}}$ & - & - \\
\hline 1971 & $1-10$ & $1-28$ & - & - \\
\hline 1972 & - & - & $2-21$ & $3-7$ \\
\hline 1973 & $1-28^{\mathbf{\Delta}}$ & $2-26^{\mathbf{A}}$ & - & - \\
\hline 1974 & $2-26$ & $3-27$ & - & - \\
\hline 1975 & - & - & $1-1,12-24$ & $2-6,12-28$ \\
\hline 1976 & $12-20^{\mathbf{\Lambda}}$ & $12-26^{\mathbf{A}}$ & - & - \\
\hline 1977 & $1-3^{\Delta}$ & $1-18^{\wedge}$ & - & - \\
\hline 1978 & - & - & $1-17^{\mathbf{4}}, 1-30$ & $1-20^{\mathbf{A}}, 2-3$ \\
\hline 1979 & $2-20$ & $3-5$ & $1-23,2-6,11-24$ & $1-28,2-11,12-7$ \\
\hline 1981 & $11-30^{\mathbf{4}}$ & $12-8^{\mathbf{4}}$ & $1-29,2-16$ & $2-9,2-27$ \\
\hline 1982 & - & - & $1-24^{\mathbf{\Lambda}}$ & $2-4^{\mathbf{A}}$ \\
\hline 1983 & $2-23^{\wedge}$ & $3-4^{\mathbf{A}}$ & $1-27^{\boldsymbol{A}}$ & $2-16^{\boldsymbol{\Lambda}}$ \\
\hline 1984 & $2-19^{\mathbf{\Lambda}}, 12-30$ & $3-20^{\mathbf{\Lambda}}, 1985-1-16$ & - & - \\
\hline 1986 & - & - & $1-20,2-15$ & $1-24,2-22$ \\
\hline 1987 & $1-16^{\mathbf{\Lambda}}, 12-7^{\mathbf{\Lambda}}$ & $2-5^{\mathbf{A}}, 12-19^{\mathbf{A}}$ & - & - \\
\hline 1989 & $2-12^{\wedge}$ & $2-28^{\wedge}$ & - & - \\
\hline 1990 & - & - & $2-5^{\mathbf{A}}$ & $2-27^{\boldsymbol{\Lambda}}$ \\
\hline 1991 & $1-20^{\wedge}$ & $2-16^{\mathbf{A}}$ & - & - \\
\hline 1992 & - & - & $1-11^{\mathbf{\Lambda}}$ & $1-24^{\boldsymbol{\Perp}}$ \\
\hline 1993 & $12-30^{\mathbf{\Lambda}}$ & $1994-1-8^{\mathbf{\Lambda}}$ & $2-15$ & $2-22$ \\
\hline 1995 & $2-9^{\mathbf{A}}$ & $2-15^{\wedge}$ & - & - \\
\hline 1996 & - & - & $2-17$ & $3-6$ \\
\hline 1997 & - & - & $12-19^{\mathbf{A}}$ & $1-11^{\mathbf{\Delta}}$ \\
\hline 1998 & $1-5^{\mathbf{\Lambda}}, 12-14^{\mathbf{\Lambda}}$ & $1-11^{\mathbf{\Lambda}}, 1999-1-14^{\mathbf{\Lambda}}$ & - & - \\
\hline 1999 & $2-23^{\wedge}$ & $3-6^{\mathbf{4}}$ & - & - \\
\hline 2001 & $1-31^{\wedge}, 12-23$ & $2-21^{\mathbf{A}}, 2002-1-10$ & - & - \\
\hline 2002 & $2-13^{\Delta}$ & $3-5^{\mathbf{A}}$ & - & - \\
\hline
\end{tabular}

Note: ${ }^{\mathbf{\Lambda}}$ an SSW downward propagating event; \#-\# the date of an SSW event in the form of month-day.

6 out of 21 minor SSW events could propagate downward. This indicates that major SSW events spread more easily downward to the troposphere than minor ones do.

Figure 1 shows the composite of geopotential height anomalies in the polar region for the downward propagating and the nondownward propagating SSW events, respectively, during the 120-day period centered on the SSW events. Here day 0 is defined as the day of the maximum anomaly at $10 \mathrm{hPa}$. The vertical axis represents the height and the horizontal axis the lead (negative) or lag (positive) of the $10 \mathrm{hPa}$ maximum anomalies' geopotential height. The selected abnormal downward propagating events (Figure 1(a)) have apparent downward positive anomalies below $150 \mathrm{hPa}$ after day 0 , while the nondownward propagating events (Figure 1(b)) show negative anomalies below the $150 \mathrm{hPa}$ height. This result suggests that the above method to select downward and nondownward propagating events is efficient and valid.

This study also considered planetary wave propagation in the vertical direction with two-dimensional EP flux calculations, using the EP flux of planetary waves. The EP flux is defined as follows [31]:

$$
F=\left(-\rho a \cos \varphi \overline{u^{\prime} v^{\prime}}, \rho a \cos \varphi \frac{R f}{H N^{2}} \overline{v^{\prime} T^{\prime}}\right),
$$

where $F$ is the EP flux, $\rho$ the air density, $a$ the radius of the Earth, $\varphi$ the latitude, $R$ the constant of the air, $f$ the Coriolis parameter, $H$ the scale height, $u$ and $v$ the zonal and meridional winds, respectively, and $T$ the temperature. In this study, the wavenumbers 1-3 are extracted with Fourier analysis method. Composite analyses are performed and the 


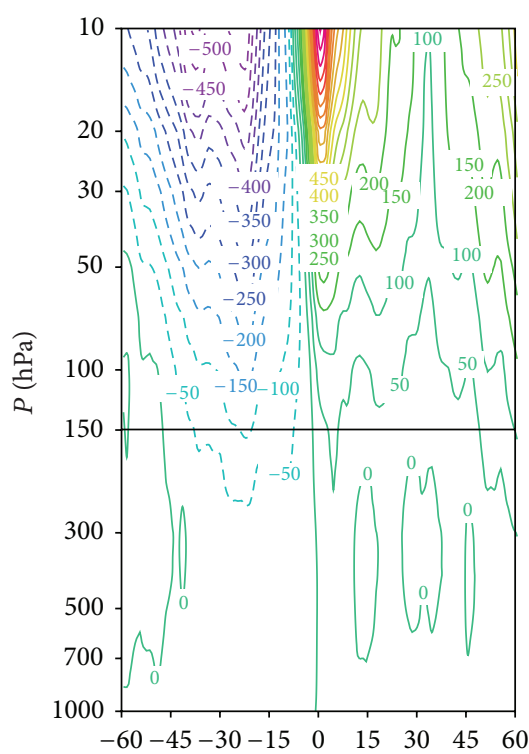

(a)

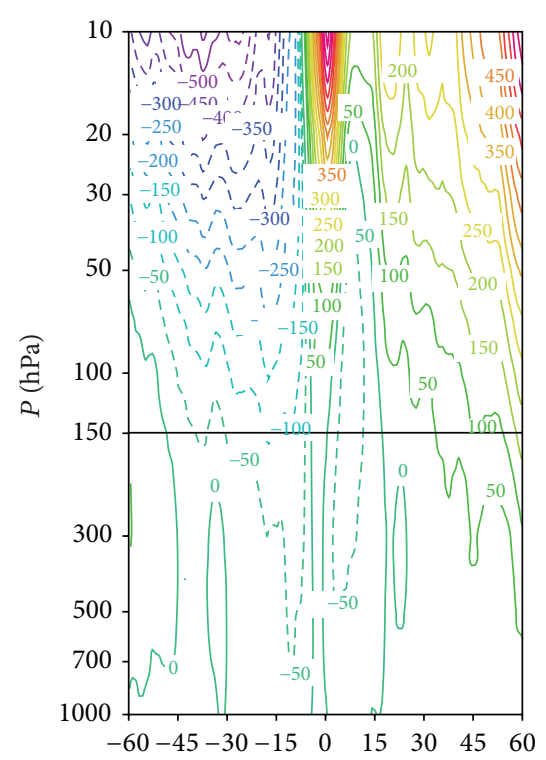

(b)

FIGURE 1: Composite of geopotential height anomalies of downward propagating SSW and nondownward propagating events: (a) downward propagating events; (b) nondownward propagating events. The time axis extends from 60 days before day 0 until 60 days afterward. The contour intervals are $50 \mathrm{gpm}$.

confidence levels are evaluated with a two-tailed Student's $t$ test.

\section{Impact of SSW on the Middle and Lower Troposphere}

During a major SSW event, the stratospheric circulation changes dramatically, and the westerly zonal winds that prevail at $10 \mathrm{hPa}$ become the easterly winds [1-3]. After the SSW event, the stratospheric anomalies may propagate downward to the troposphere in the middle and high latitudes $[4,5]$. Such features are well captured by the zonal-mean zonal wind anomalies shown in Figure 2, which is the composite based on the 28 downward propagating SSW events. During the peak (day -10 +10) of the SSW events, there are clear easterly anomalies that center at $60^{\circ} \mathrm{N}$ at about $1 \mathrm{hPa}$ (Figure $2(\mathrm{a})$ ). These easterly anomalies are originally confined in the stratosphere at the middle and high latitudes, and the easterly anomalies in the troposphere are very weak (Figure 2(a)). The center of the easterly anomalies propagates downward to about $10 \mathrm{hPa}$ afterwards (Figure 2(b)). During day $+10 \sim$ +40 , the maximum easterly anomalies appear at $10 \mathrm{hPa}$ height at $60^{\circ} \mathrm{N}$, and clear easterly anomalies can be observed in the troposphere and even near the surface (Figure 2(b)). Meanwhile, the westerly winds are gradually restored at $1 \mathrm{hPa}$ from about $45^{\circ} \mathrm{N}$. Although the easterly circulation is in its slipping stage in the middle stratosphere, it still dominates the lower stratosphere and the whole troposphere.

In order to investigate the impact of the SSW on the EAWM, we composited the atmospheric circulation anomalies during (day $-10 \sim+10)$ and after (day $+10 \sim+40)$ the downward propagation of the SSW signals. Figure 3 shows the distribution of the $1000 \mathrm{hPa}$ geopotential height anomalies during (day $-10 \sim+10)$ and after (day $+10 \sim+40)$ the SSW. During the peak of the SSW events (Figure 3(a)), the $1000 \mathrm{hPa}$ geopotential height filed features significant positive anomalies region over the eastern part of the Eurasian continent and negative anomalies over the North Pacific, exhibiting clear wave-like structure. These anomalies overlap the Siberian high and the Aleutian low, indicating that both systems are strengthened. This is reasonable because, during the SSW events, the planetary waves are more active and have larger amplitude. Given that the Siberian high and the Aleutian low are manifestations of the planetary waves at the surface [29], the two systems both amplified during this process. In this situation, the pressure gradient between the Asian continent and the North Pacific is significantly enhanced and facilitates the strengthening of the EAWM. After the peak of the SSW (Figure 3(b)), the wave-like structure diminished. Instead, the polar region and the mid-latitude region are occupied by positive and negative geopotential height anomalies, respectively. This structure is quite zonal-symmetric and resembles the negative phase of AO. A slight difference of this structure form the conventional $\mathrm{AO}[21,22]$ is that the anomalies over the North Pacific are stronger than those over the North Atlantic (Figure 3(b)), so it resembles the NPO [19] to some extent. In this situation, the Siberian high weakens significantly, but the Aleutian low amplifies over its southern part. Therefore, the pressure gradient in between is enhanced along the coasts and weakened in the East Asian inland.

Another significant feature of the East Asian winter atmospheric circulation is the deep coastal trough in the midtroposphere [32, 33], so we further examined the East Asian trough during and after the SSW. Figure 4 shows the $500 \mathrm{hPa}$ geopotential height anomalies during and after the peak of the SSW. During the peak of the SSW (Figure 4(a)), a roughly 


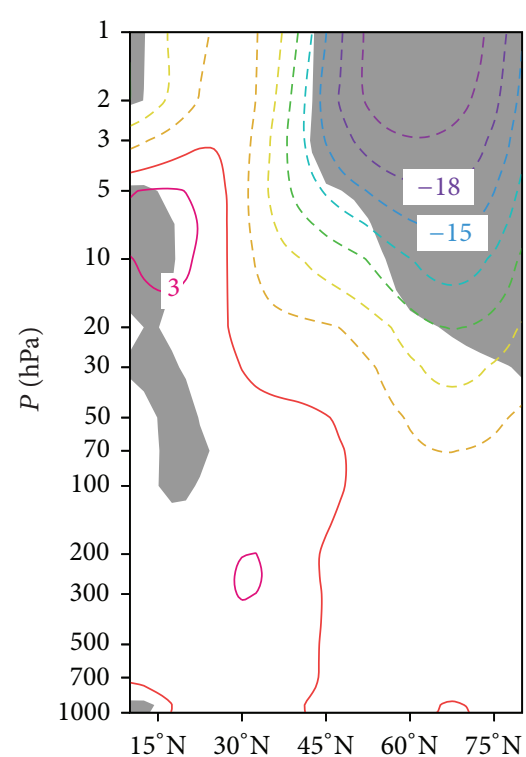

(a) $(-10 /+10)$

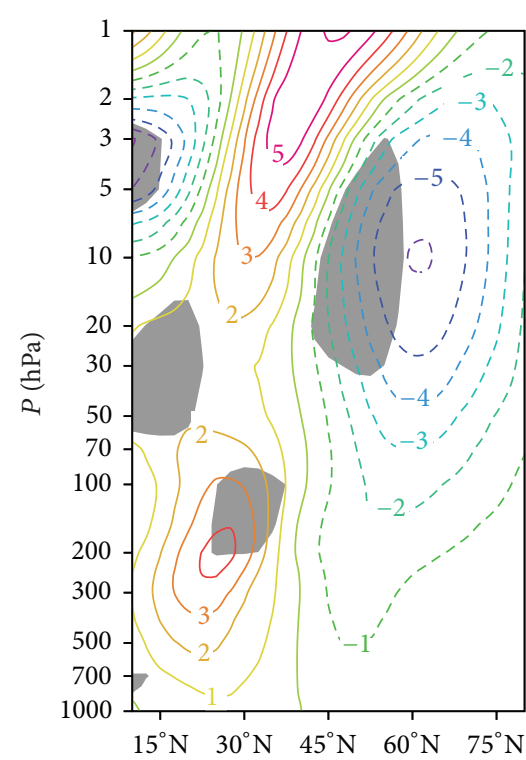

(b) $(+10 /+40)$

FIGURE 2: Distribution of zonal mean wind anomalies during and after the peak of SSW: (a) day $-10 \sim+10$ mean; (b) day $+10 \sim+40$ mean. Unit: $\mathrm{m} \mathrm{s}^{-1}$.

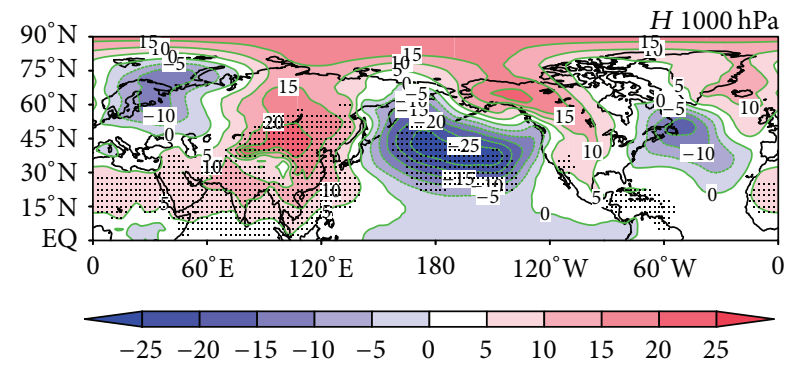

(a) $-10 /+10$

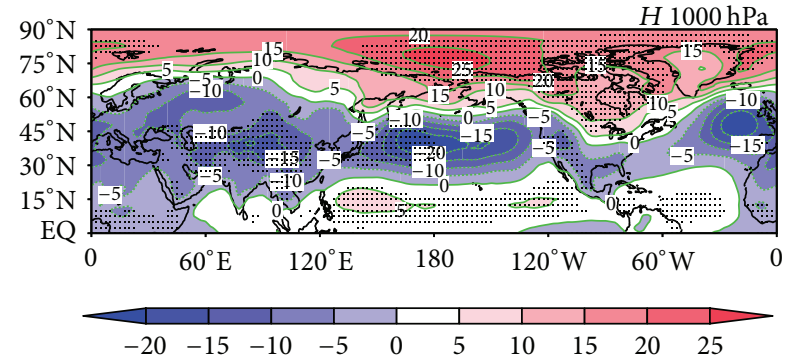

(b) $+10 /+40$

FIGURE 3: Distribution of $1000 \mathrm{hPa}$ geopotential height anomalies during and after the peak of SSW: (a) day $-10 \sim+10$ mean; (b) day $+10 \sim+40$ mean. Unit: gpm; the dots indicate $99 \%$ confidence levels; the contour and the shading both indicate the geopotential height anomalies.

wavenumber- 3 pattern is observed north of $45^{\circ} \mathrm{N}$, corresponding to the wave-like pattern of $1000 \mathrm{hPa}$ (Figure 3(a)). The geopotential height filed is significantly negative around Japan (Figure 4(a)), indicating the enhanced East Asian trough and thereby the EAWM. After the peak of the SSW, the circulation at $500 \mathrm{hPa}$ is more zonally symmetric and the wavenumber- 3 pattern is slightly weakened, resembling the negative phase of both AO and NPO (Figure 4(b)). The NPO/WP pattern is especially clear and it exhibits a meridional dipole over the North Pacific. Compared with the peak of the SSW (Figure 4(a)), the anomalous negative geopotential height center over the Pacific is located more eastward (Figure 4(b)). Hence, it suggests that the East Asian trough not only deepens but also shifts eastward. This configuration is conducive to cold episode along the coastal areas of East Asia in the lower troposphere [33].

The decreased temperature anomalies during and after the peak of the SSW are shown in Figure 5. During the peak of the SSW (Figure 5(a)), the northern and central parts of East
Asia show quite significant cooling. This is consistent with the strong Siberian high (Figure 3(a)) and East Asian trough (Figure 4(b)). After the peak of the SSW (Figure 5(b)), East Asia shows quite contrasting temperature patterns between inland and coastal regions. The inland and the Southeast regions show clear warming, whereas the coastal areas and Japan show significant cooling. The inland warming can be attributed to the weakened Siberian high (Figure 3(b)). The coastal cooling can be attributed to the enhanced Aleutian low over its southern portion and the attendant enhanced pressure gradient (Figure 3(b)), as well as the deepened and eastward shifted East Asian trough (Figure 4(b)).

To get a clearer picture of the above interpretation, the wind anomalies at $850 \mathrm{hPa}$ are shown in Figure 6. During the peak of SSW (Figure 6(a)), significant northerly anomalies prevail in a wide longitudinal range from northeast China to the coast of East Asia and even east of Japan. This configuration can carry cold air from the higher latitudes and result in lower-than-normal temperatures in all of East 


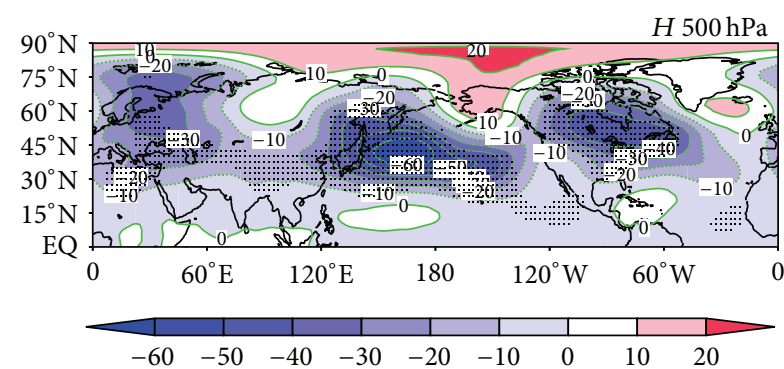

(a) $-10 /+10$

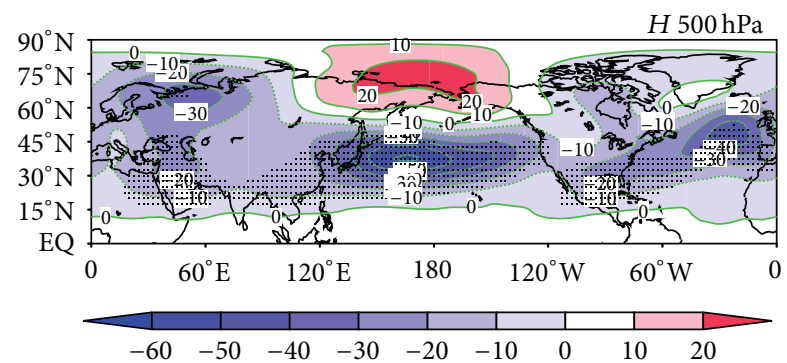

(b) $+10 /+40$

FIGURE 4: Distribution of $500 \mathrm{hPa}$ geopotential height anomalies during and after the peak of SSW: (a) day $-10 \sim+10$ mean; (b) day $+10 \sim+40$ mean. Unit: gpm; the dots indicate $99 \%$ confidence levels; the contour and the shading both indicate the geopotential height anomalies.

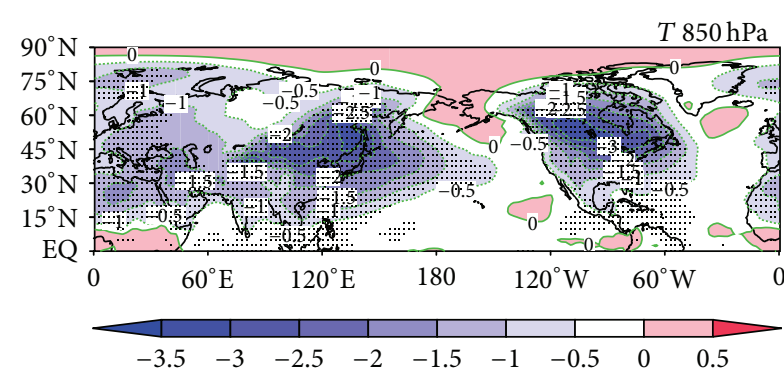

(a) $-10 /+10$

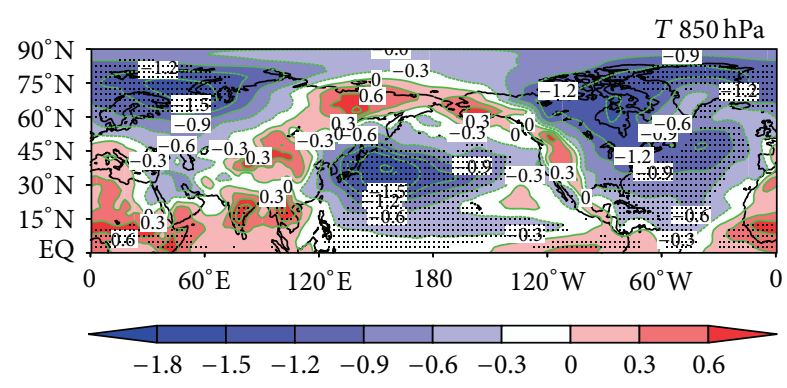

(b) $+10 /+40$

FIGURE 5: Distribution of $850 \mathrm{hPa}$ temperature anomalies during and after the peak of SSW: (a) day $-10 \sim+10$ mean; (b) day +10 +40 mean. Unit: K; the dots indicate $99 \%$ confidence levels; the contour and the shading both indicate the temperature anomalies.

Asia (Figure 5(a)). After the peak of the SSW (Figure 6(b)), in contrast, the northerly anomalies only prevail around and to the east of Japan, and southerly anomalies are observed over Southeast Asia. Therefore, cooling is only confined to the coastal region and around Japan, while warming is observed in the inland of East Asia (Figure 5(b)).

\section{Activity of Planetary Waves during the Lifecycle of the SSW}

It is well known that a planetary wave generated in the troposphere can propagate upward, especially in winter, and can pass through the tropopause into the stratosphere [34] causing the stratosphere and troposphere to couple together. $\mathrm{AO}$ signals are able to propagate downward and impact the troposphere under some certain conditions as well $[35,36]$. Furthermore, because the NPO/WP has a quasi-positive structure [21], it may cause changes in the lower atmosphere when its high levels trigger some adjustments in Pacific geopotential height. Therefore, in this section, the activities of planetary waves in the downward propagating process of the SSW anomaly are studied by means of its corresponding EP flux and wave amplitude.

Figure 7 shows the anomalies of EP flux for wavenumbers 1 3 during different periods of the SSW. Twenty days before the SSW, stronger-than-normal EP flux is observed to propagate continuously into the stratosphere (Figures $7(\mathrm{a})-7(\mathrm{~d})$ ). This propagation is especially strong in the week before the peak of the SSW (Figure 7(d)). These anomalously upward propagating planetary waves converge in the polar stratosphere, leading to the deceleration of the stratospheric westerly winds. After 20 days of a decelerating effect on the stratospheric westerly circulation, the strength of the stratospheric polar vortex significantly decreases. When the decelerating effect reaches its maximum, the westerly turns to easterly and SSW occurs. When the SSW occurs, the establishment of the easterly circulation in the polar regions is not conducive to the upward propagation of planetary waves, so that further dispersion of the tropospheric wave energy into the stratosphere is suppressed. This process can be seen clearly from the EP flux diagrams. When the SSW begins (Figure 7(e)) the EP flux into the stratosphere weakens rapidly and anomalous downward EP flux is observed in the subpolar region (Figures 7(f)-7(i)). In this situation, it is conducive to the diabatic adjustments, and a radiative balance develops. Then, the westerly of polar night jet accelerates and the westerly circulation gradually resumes. However, the upward propagation of planetary waves remains weak (Figures 7(f)-7(i)) in both the stratosphere and the upper troposphere, and the decelerating effect of planetary waves on the polar night jet is still effective in the middle and high latitudes. This will facilitate a weak circumpolar vortex, which helps the negative phase of $\mathrm{AO}$ to maintain and propagate downward and thereby results in changes in the lower atmospheric circulation.

Figure 8 shows the amplitude anomalies of planetary waves for wavenumbers 1 to 3 . Before the peak of the SSW (Figure 8(a)), the amplitude of planetary increases in 


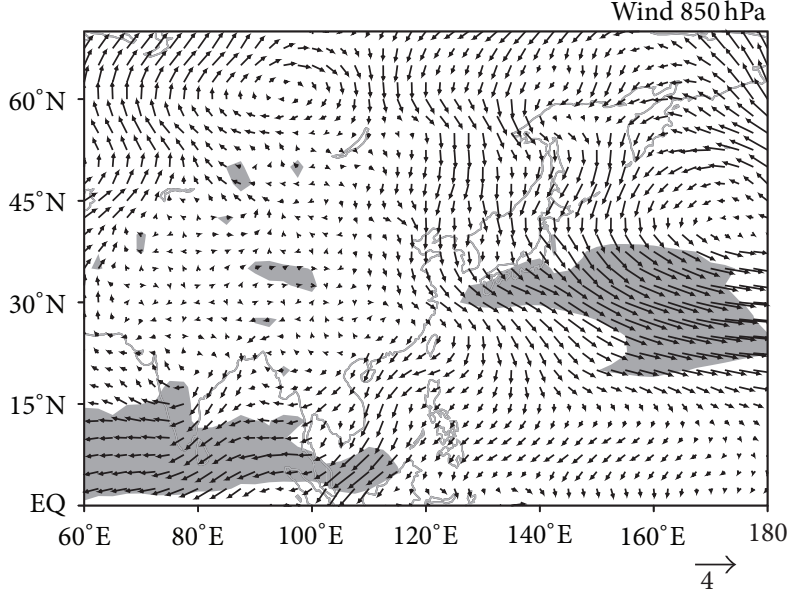

(a) $-10 /+10$

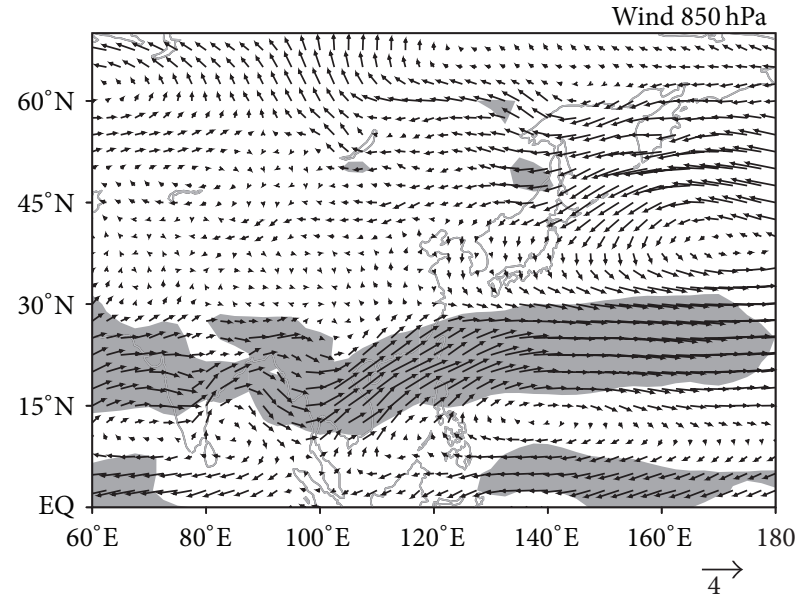

(b) $+10 /+40$

FIGURE 6: Distribution of $850 \mathrm{hPa}$ wind anomalies during and after the peak of SSW: (a) day $-10 \sim+10$ mean; (b) day $+10 \sim+40$ mean. Unit: $\mathrm{m} \mathrm{s}^{-1}$; the shadings indicate $99 \%$ confidence levels.

the region of $45^{\circ} \mathrm{N} \sim 70^{\circ} \mathrm{N}$ with the maximum being located between 300 and $200 \mathrm{hPa}$ and decreases in the regions of $30^{\circ} \mathrm{N} \sim 45^{\circ} \mathrm{N}$. The increase of wave amplitude at high latitudes is consistent with the enhanced upward propagation of planetary waves (Figures 7(a)-7(d)) that implies enhanced activity of planetary waves. After the peak of the SSW (Figure 8(b)), the pattern of amplitude of planetary waves remains similar but has opposite signs. That is, reduced amplitude is observed in $45^{\circ} \mathrm{N} \sim 70^{\circ} \mathrm{N}$, while enhanced amplitude is observed at $30^{\circ} \mathrm{N} \sim 45^{\circ} \mathrm{N}$. This is also consistent with the suppressed upward propagation of planetary waves (Figures 7(f)-7(i)) that implies weakened activity of planetary waves. The reduced wave amplitude at high latitudes $\left(45^{\circ} \mathrm{N} \sim 70^{\circ} \mathrm{N}\right)$ corresponds to a weakened Siberian high [37] and the increased wave amplitude at $30^{\circ} \mathrm{N} \sim 45^{\circ} \mathrm{N}$ corresponds to the enhanced Aleutian low in its southern portion. Therefore, these results suggest that the planetary wave play an important role in linking the SSW and the EAWM.

\section{Discussion and Conclusions}

The traditional view is that the stratosphere is only passively influenced by the troposphere, and that it is difficult for the stratosphere to influence the troposphere. However, studies over the past ten years have discovered that the stratosphere not only accepts waves and energy from the troposphere, but also sends anomalies back to the troposphere [4-11]. A key connector between the stratosphere and troposphere is the activities of planetary waves. In this study, we investigated the unique phenomenon of SSW and its impacts on the troposphere, focusing on the impacts on the EAWM.

Based on composite analysis of selected SSW events whose signals can propagate downward to the troposphere, it is found that the stratospheric polar night jet is significantly weakened during the peak of the SSW. During this period, the planetary wave-like structure in the troposphere is very strong and the enhanced amplitude of planetary waves corresponds to strong Siberian high and Aleutian low. This configuration facilitates strong northerly anomalies from Northeast China to North Pacific. Therefore, the EAWM is intensified and significant cooling is observed over all of East Asia especially over inland. After the peak of the SSW, the stratospheric easterly anomalies descend to the troposphere, while the easterly anomalies in the upper stratosphere begin to diminish and restore towards the westerly circulation. During this period, the tropospheric circulation anomalies are quite zonally symmetric and feature clear negative phases of AO and NPO. The Siberian high is weakened but the southern portion of the Aleutian low is strengthened. The mid-tropospheric East Asian trough deepens and shifts eastward. In this situation, the $850 \mathrm{hPa}$ northerly anomalies are only observed around and to the east of Japan. Therefore, significant cooling is observed over coastal East Asia centered over Japan whereas clear warming is observed in the East Asian inland.

The activities of planetary waves were also examined during the lifecycle of the SSW. Before the occurrence of the SSW, there is stronger-than-normal upward propagating EP flux of planetary waves towards the polar stratosphere, leading to a decrease of the stratospheric circumpolar westerly winds. When the SSW occurs, the upward propagation of EP flux weakens because the significantly weakened stratospheric westerly makes it difficult for the planetary wave to propagate upward. The decreased upward propagation of planetary waves favors an adjustment of the diabatic radiation balance to develop, and it produces westerly acceleration in the upper stratosphere and a gradual recovery of westerly circulation. Nevertheless, the westerly circulation continues to slow down in the lower stratosphere and upper troposphere, being conducive to the downward propagation of the negative AO signal from the stratosphere to the troposphere. Thus, the SSW could affect the atmospheric circulation of the lower troposphere. Accompanied with the above-mentioned anomalous propagation of the planetary waves, the amplitude 


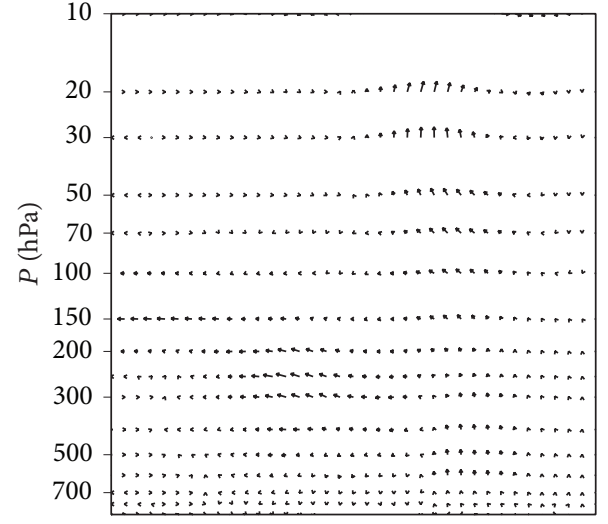

(a)

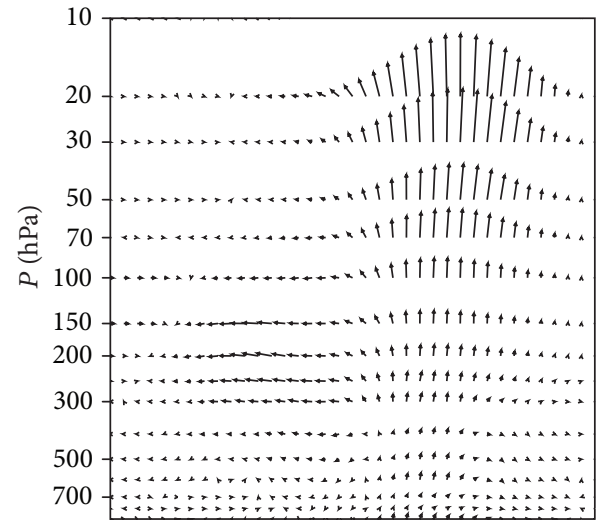

(d)

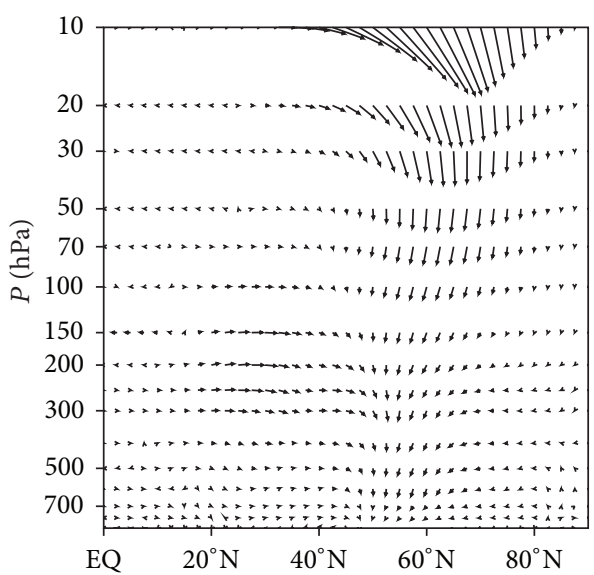

(g)

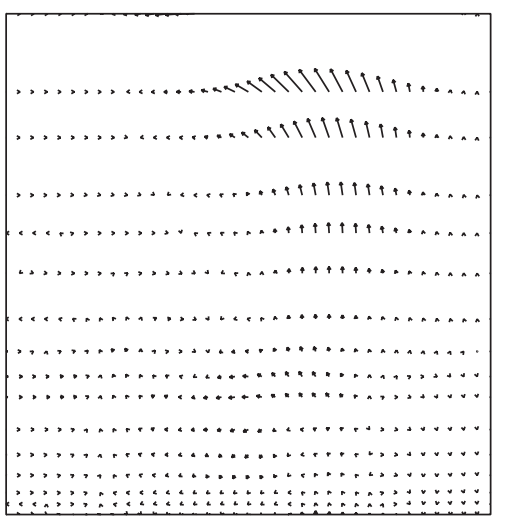

(b)

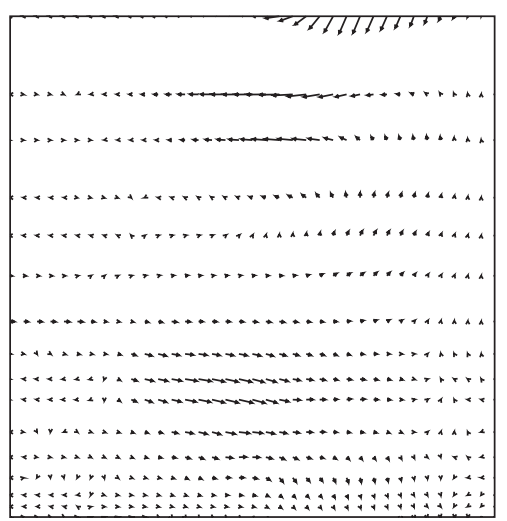

(e)

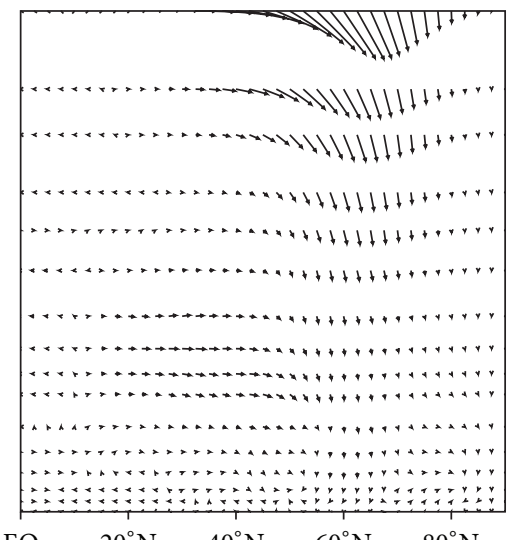

EQ $\quad 20^{\circ} \mathrm{N} \quad 40^{\circ} \mathrm{N} \quad 60^{\circ} \mathrm{N} \quad 80^{\circ} \mathrm{N}$

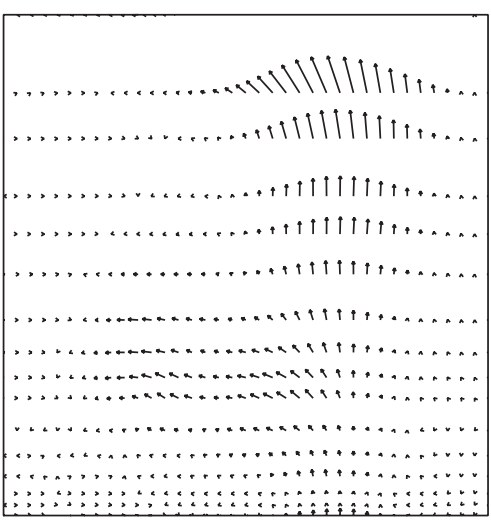

(c)

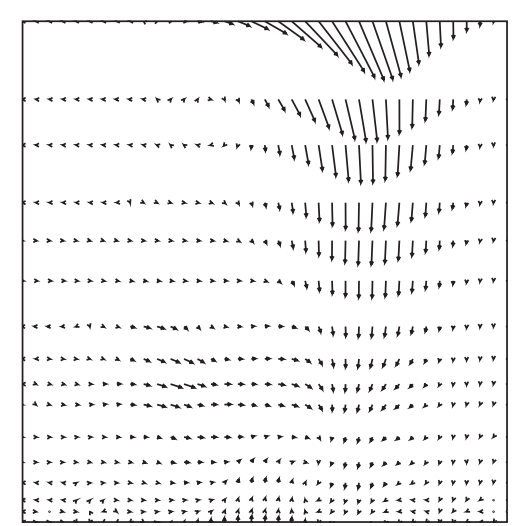

(f)

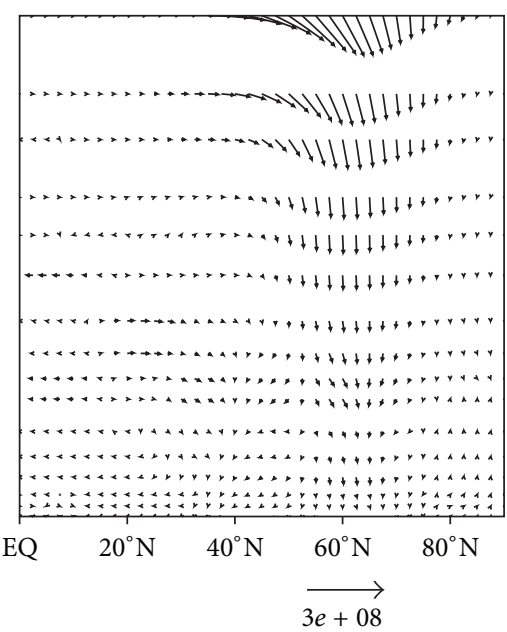

(i)

FIGURE 7: Evolution of EP flux during the lifecycle of SSW: (a) day -22 -18 mean; (b) day -17 -13 mean; (c) day -12 -8 mean; (d) day

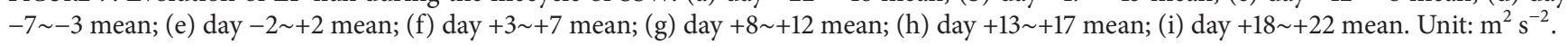

of the planetary waves decreases after the SSW at $45^{\circ} \mathrm{N} \sim 70^{\circ} \mathrm{N}$ and increases at $30^{\circ} \mathrm{N} \sim 45^{\circ} \mathrm{N}$. It weakens the Siberian high and strengthens the southern portion of the Aleutian low, leading to the observed cooling around Japan and warming over East Asian inland.

In this study, the temperature anomalies over East Asia during and after the SSW events are investigated and explained from a point of view of altered atmospheric circulations. The wave-like circulation during the peak of the SSW and the zonally symmetric circulation after the peak of the SSW are quite contrasting. The different activities of planetary waves are suggested to be crucial in this process. Nevertheless, the mechanism of the downward propagation of the AO signal from the stratosphere to the troposphere 


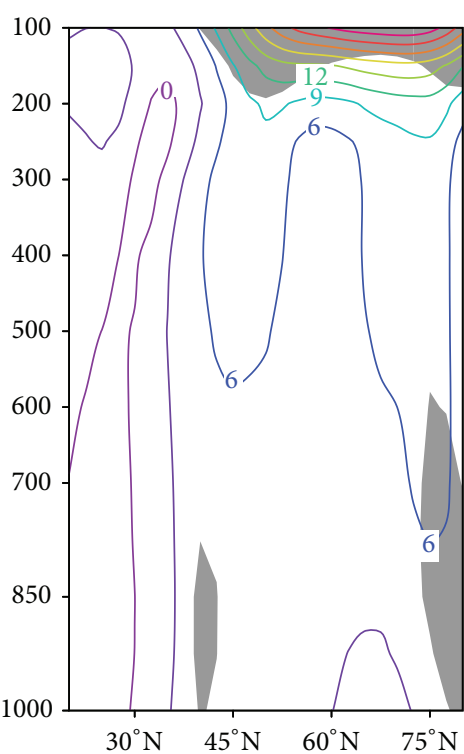

(a) $-10 /+10$

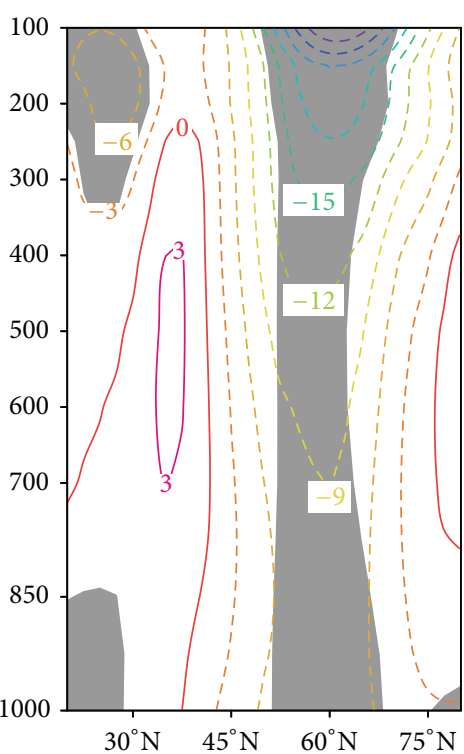

(b) $+10 /+40$

FIGURE 8: The anomalous amplitude of planetary wave numbers 1 to 3 before and after the peak of SSW: (a) day $-10 \sim-40$ mean; (b) day $+10 \sim+40$ mean. Unit: gpm.

remains unanswered. This is a difficult and intriguing issue that needs more theoretical studies.

\section{Conflict of Interests}

The authors declare that there is no conflict of interests regarding the publication of this paper.

\section{Acknowledgments}

This work was supported by National Natural Science Foundation of China $(41475037,41405031)$ and Sichuan Youth Fund (2014JQ0019).

\section{References}

[1] R. Scherhag, "Die explosionsartigen Stratosphärener wärmungen des Spätwinters 1951/52," Berichte des Deutschen Wetterdienstes in der US-Zone, vol. 6, no. 38, pp. 51-63, 1952.

[2] A. J. Charlton and L. M. Polvani, "A new look at stratospheric sudden warmings. Part I. Climatology and modeling benchmarks," Journal of Climate, vol. 20, no. 3, pp. 449-469, 2007.

[3] N. J. Matthewman, J. G. Esler, A. J. Charlton-Perez, and L. M. Polvani, "A new look at stratospheric sudden warmings. Part III: polar vortex evolution and vertical structure," Journal of Climate, vol. 22, no. 6, pp. 1566-1585, 2009.

[4] R. S. Quiroz, "The tropospheric-stratospheric polar vortex breakdown of January 1977," Geophysical Research Letters, vol. 4, no. 4, pp. 151-154, 1977.

[5] M. P. Baldwin and T. J. Dunkerton, "Propagation of the Arctic Oscillation from the stratosphere to the troposphere," Journal of Geophysical Research D: Atmospheres, vol. 104, no. 24, pp. 30937-30946, 1999.
[6] M. P. Baldwin, D. B. Stephenson, D. W. J. Thompson, T. J. Dunkerton, A. J. Charlton, and A. O’Neill, "Stratospheric memory and skill of extended-range weather forecasts," Science, vol. 301, no. 5633, pp. 636-640, 2003.

[7] M. P. Baldwin and D. W. J. Thompson, "A critical comparison of stratosphere-troposphere coupling indices," Quarterly Journal of the Royal Meteorological Society, vol. 135, no. 644, pp. 1661$1672,2009$.

[8] L. Li, C.-Y. Li, Y.-K. Tan, and C.-H. Chen, "Stratospheric sudden warming impacts on the weather climate in China and its role in the influences of ENSO," Chinese Journal of Geophysics, vol. 53, no. 7, pp. 1529-1542, 2010 (Chinese).

[9] S. Deng, Y. Chen, T. Luo, Y. Bi, and H. Zhou, "The possible influence of stratospheric sudden warming on East Asian weather," Advances in Atmospheric Sciences, vol. 25, no. 5, pp. 841-846, 2008.

[10] D. M. Mitchell, L. J. Gray, J. Anstey, M. P. Baldwin, and A. J. Charlton-Perez, "The influence of stratospheric vortex displacements and splits on surface climate," Journal of Climate, vol. 26, no. 8, pp. 2668-2682, 2013.

[11] L. Wang and W. Chen, "Downward Arctic Oscillation signal associated with moderate weak stratospheric polar vortex and the cold December 2009," Geophysical Research Letters, vol. 37, no. 9, 2010.

[12] M. Cai and C.-S. Shin, "A total flow perspective of atmospheric mass and angular momentum circulations: boreal winter mean state," Journal of the Atmospheric Sciences, vol. 71, no. 6, pp. 2244-2263, 2014.

[13] Y. Yu, M. Cai, R. Ren, and H. M. van den Dool, "Relationship between warm airmass transport into the upper polar atmosphere and cold air outbreaks in winter," Journal of the Atmospheric Sciences, vol. 72, no. 1, pp. 349-368, 2015.

[14] J. C. L. Chan and C. Li, “The East Asia winter monsoon," in East Asian Monsoon, chapter 2, pp. 54-106, World Scientific, 2004, (Chinese). 
[15] R. Huang, J. Chen, L. Wang, and Z. Lin, "Characteristics, processes, and causes of the spatio-temporal variabilities of the East Asian monsoon system," Advances in Atmospheric Sciences, vol. 29, no. 5, pp. 910-942, 2012.

[16] D.-Y. Gong, S.-W. Wang, and J.-H. Zhu, "East Asian winter monsoon and Arctic Oscillation," Geophysical Research Letters, vol. 28, no. 10, pp. 2073-2076, 2001.

[17] B. Wu and J. Wang, "Possible impacts of winter Arctic Oscillation on Siberian High, the East Asian winter monsoon and sea-ice extent," Advances in Atmospheric Sciences, vol. 19, no. 2, pp. 297-320, 2002.

[18] C. He and J. H. He, "Relation between arctic oscillation and North China air temperature in winter," Journal of Nanjing Institute of Meteorology, vol. 26, no. 1, pp. 1-7, 2003 (Chinese).

[19] J. H. Ju, J. Z. Ren, and J. M. Lv, "Effect of interdecadal variation of arctic oscillation on temperature increasing in north of east Asian winter," Plateau Meteorology, vol. 23, no. 4, pp. 429-434, 2004 (Chinese).

[20] J. P. Li, Y. Q. Yu, and W. Chen, "Physical significance of the arctic oscillation and its relationship with east Asian atmospheric circulation," in Effect of Air-Sea Interaction on Climate Change in China, pp. 169-176, Meteorological Press, Beijing, China, 2005, (Chinese).

[21] L. Wang, W. Chen, S. Fong et al., "The seasonal March of the north pacific oscillation and its association with the interannual variations of China's climate in boreal winter and spring," Chinese Journal of Atmospheric Science, vol. 35, no. 3, pp. 393402, 2011 (Chinese).

[22] L. Wang and W. Chen, "An intensity index for the East Asian winter monsoon," Journal of Climate, vol. 27, no. 6, pp. 23612374, 2014.

[23] D. W. J. Thompson and J. M. Wallace, "The Arctic oscillation signature in the wintertime geopotential height and temperature fields," Geophysical Research Letters, vol. 25, no. 9, pp. 12971300, 1998.

[24] D. W. J. Thompson and J. M. Wallace, "Annular modes in the extratropical circulation. Part I: month-to-month variability," Journal of Climate, vol. 13, no. 5, pp. 1000-1016, 2000.

[25] K. Kodera and Y. Kuroda, "Tropospheric and stratospheric aspects of the Arctic Oscillation," Geophysical Research Letters, vol. 27, no. 20, pp. 3349-3352, 2000.

[26] M. P. Baldwin, D. W. J. Thompson, E. F. Shuckburgh, W. A. Norton, and N. P. Gillett, "Weather from the stratosphere?" Science, vol. 301, no. 5631, pp. 317-319, 2003.

[27] B. Christiansen, "Downward propagation and statistical forecast of the near-surface weather," Journal of Geophysical Research D: Atmospheres, vol. 110, no. 14, pp. 1-10, 2005.

[28] W. Chen, K. Wei, L. Wang, and Q. Zhou, "Climate variability and mechanisms of the East Asian winter monsoon and the impact from the stratosphere," Chinese Journal of Atmospheric Sciences, vol. 37, no. 2, pp. 425-438, 2013 (Chinese).

[29] W. Chen and K. Wei, "Anomalous propagation of the quasistationary planetary waves in the atmosphere and its roles in the impact of stratosphere on the east Asian winter climat," Advances in Earth Science, vol. 24, no. 3, pp. 272-285, 2009 (Chinese).

[30] W. Chen, M. Takahashi, and H. F. Graf, "Interannual variations of stationary planetary wave activity in the northern winter troposphere and stratosphere and their relations to NAM and SST," Journal of Geophysical Research: Atmospheres, vol. 108, no. D24, 2003.
[31] W. Chen, S. Yang, and R.-H. Huang, "Relationship between stationary planetary wave activity and the East Asian winter monsoon," Journal of Geophysical Research D: Atmospheres, vol. 110, no. 14, 2005.

[32] L. X. Chen, East Asian Monsoon, Meteorological Press, 1991.

[33] L. Wang, W. Chen, W. Zhou, and R. Huang, "Interannual variations of East Asian trough axis at $500 \mathrm{hPa}$ and its association with the East Asian winter monsoon pathway," Journal of Climate, vol. 22, no. 3, pp. 600-614, 2009.

[34] W. Chen and R. H. Huang, "The propagation and transport effect of planetary waves in the Northern Hemisphere winter," Advances in Atmospheric Sciences, vol. 19, no. 6, pp. 1113-1126, 2002.

[35] B. Christiansen, "Downward propagation of zonal mean zonal wind anomalies from the stratosphere to the troposphere: Model and reanalysis," Journal of Geophysical Research D: Atmospheres, vol. 106, no. 21, pp. 27307-27322, 2001.

[36] R. X. Black, "Stratospheric forcing of surface climate in the Arctic oscillation," Journal of Climate, vol. 15, no. 3, pp. 268-277, 2002.

[37] W. Chen, S. Yang, and R.-H. Huang, "Relationship between stationary planetary wave activity and the East Asian winter monsoon," Journal of Geophysical Research D: Atmospheres, vol. 110, no. D14, 2005. 

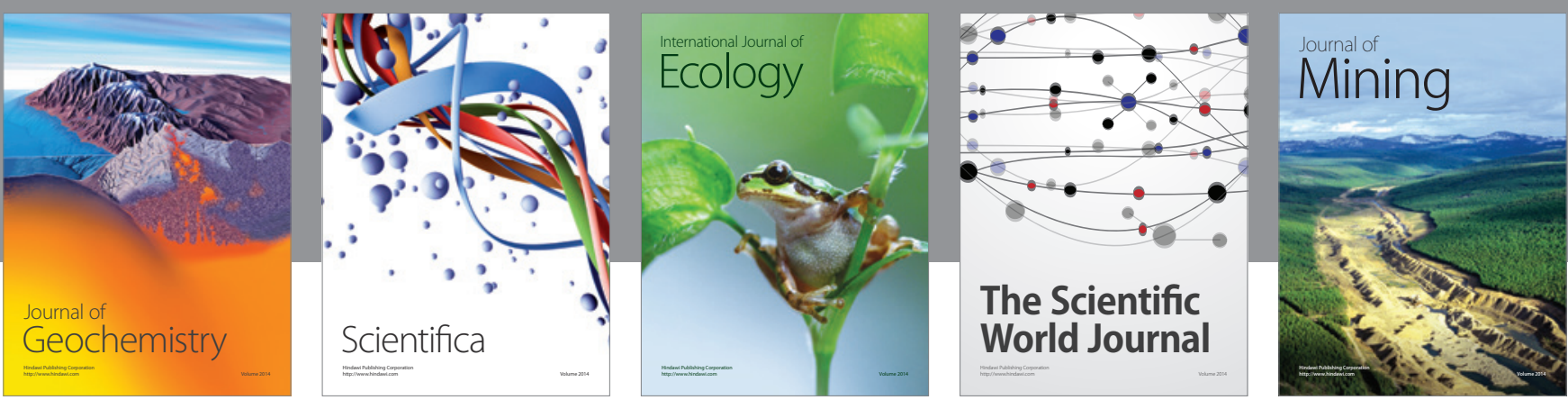

The Scientific World Journal
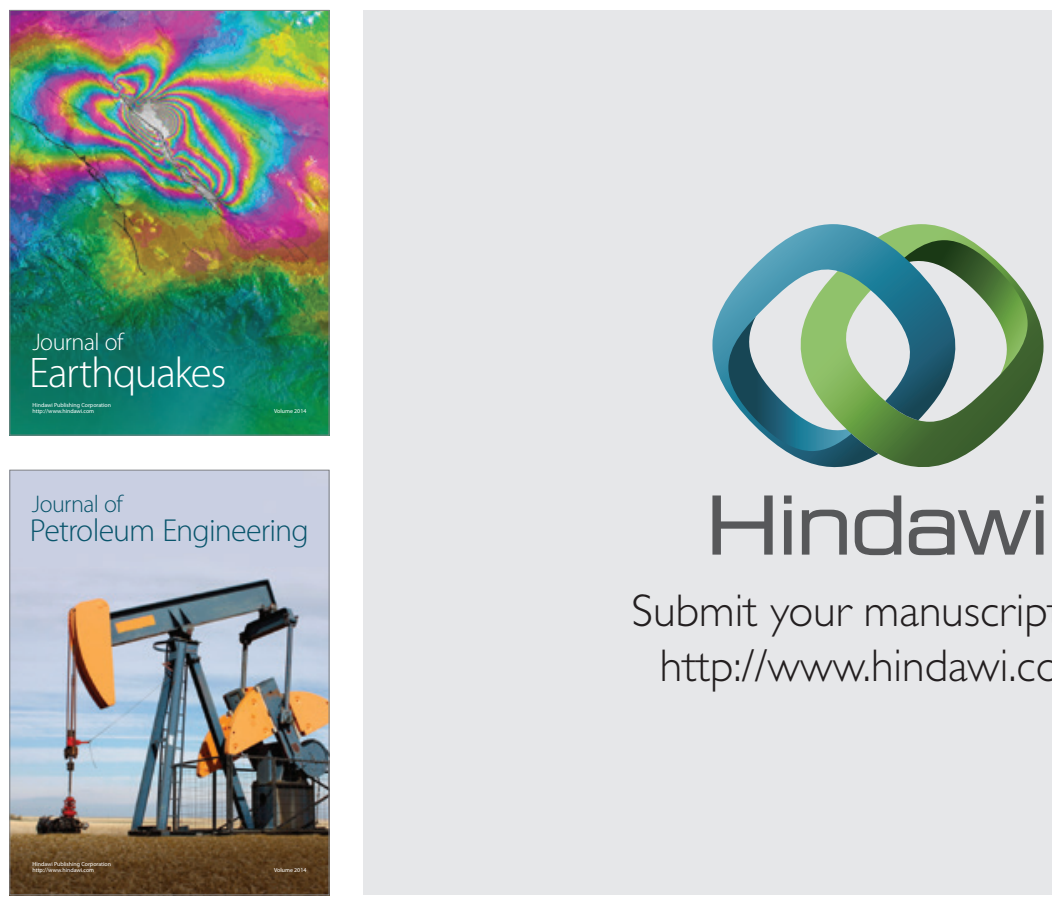

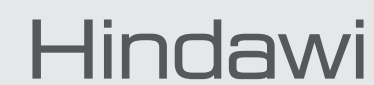

Submit your manuscripts at

http://www.hindawi.com
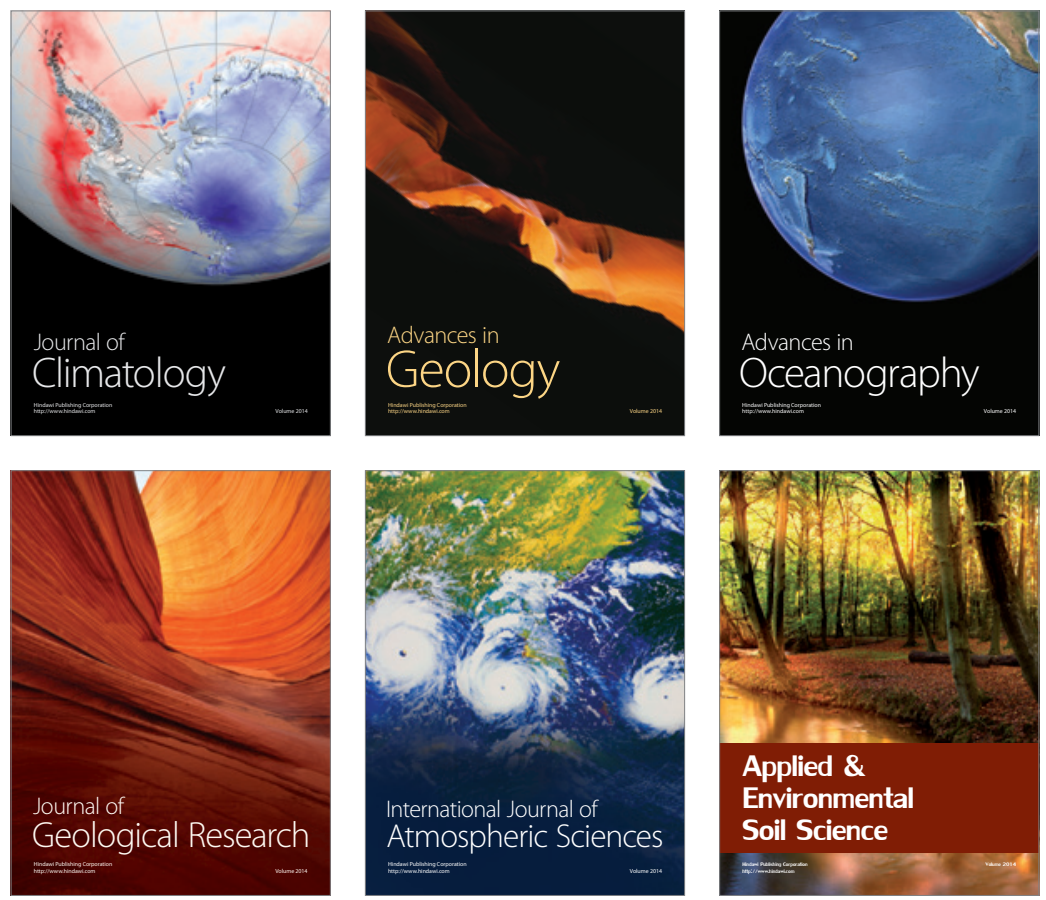
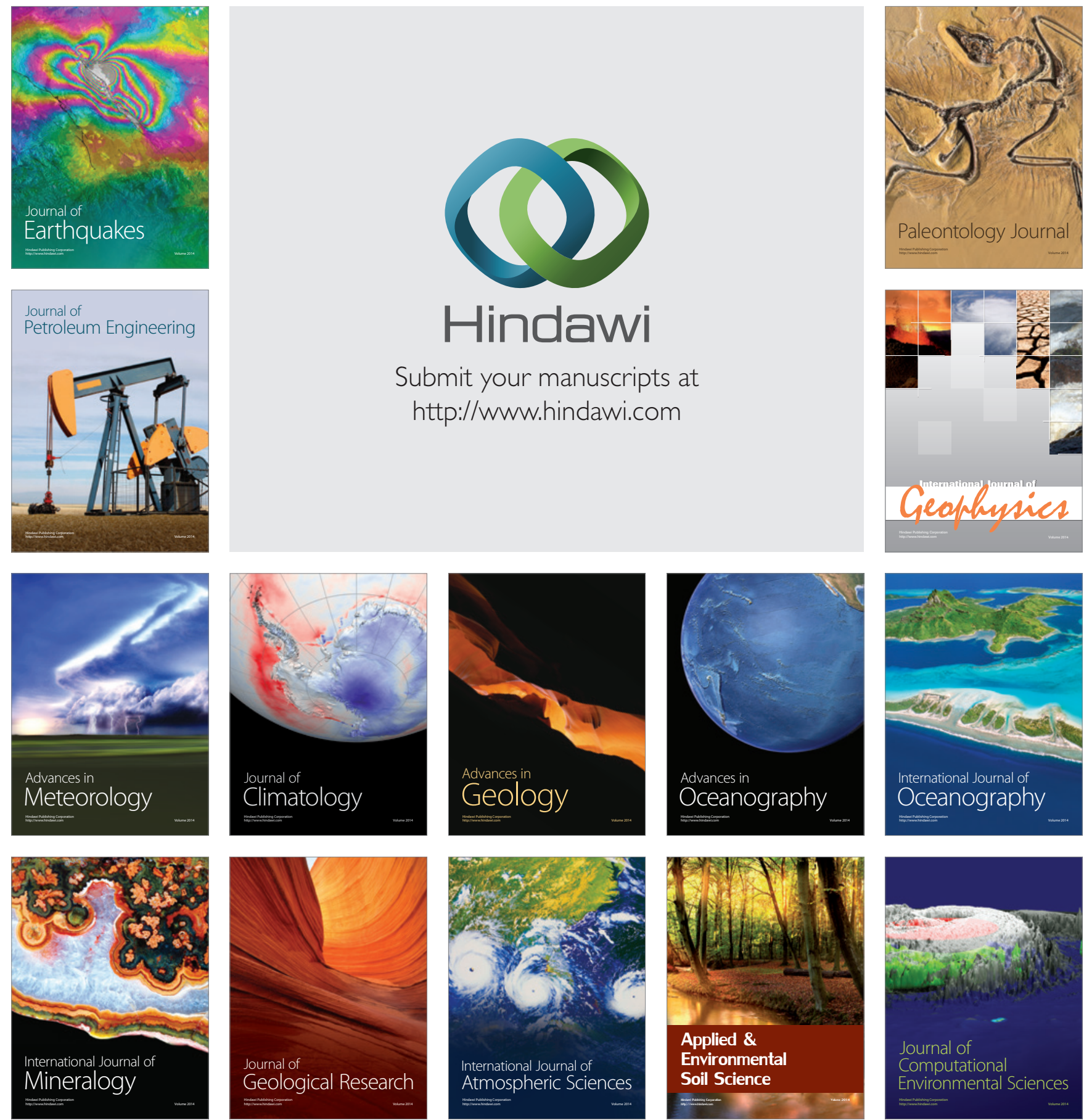